\title{
Effect of Ramadan fasting on some indices of insulin resistance and components of the metabolic syndrome in healthy male adults
}

\author{
Z. Vahdat Shariatpanahi ${ }^{1 *}$, M. Vahdat Shariatpanahi ${ }^{2}$, S. Shahbazi ${ }^{3}$, A. Hossaini $^{4}$ and A. Abadi ${ }^{5}$ \\ ${ }^{1}$ Faculty of Nutrition and Food Industry, Shaheed Beheshti University of Medical Sciences, Tehran, Iran \\ ${ }^{2}$ Department of Psychiatry, Islamic Azad University of Medical Sciences, Tehran, Iran \\ ${ }^{3}$ Department of Internal Medicine, Shaheed Beheshti University of Medical Sciences, Tehran, Iran \\ ${ }^{4}$ Iran University of Medical Sciences, Tehran, Iran \\ ${ }^{5}$ Department of Biostatistics, Shaheed Beheshti University of Medical Sciences, Tehran, Iran \\ (Received 28 February 2007 - Revised 26 October 2007 - Accepted 26 October 2007 - First published online 6 December 2007)
}

\begin{abstract}
The purpose of the present study was to evaluate the effect of Ramadan fasting on insulin sensitivity in subjects with the metabolic syndrome. Males ( $n$ 55; age 34.1 (SD 8.9) years) with the metabolic syndrome were studied. Blood pressure, waist circumference, body weight, HDL-cholesterol (HDL-C), TAG, fasting plasma glucose (FPG), fasting blood insulin and insulin resistance indices (quantitative insulin sensitivity check index (QUICKI), homeostasis model assessment of insulin resistance (HOMA-IR) and reciprocal index of HOMA-IR (1/HOMA-IR)) were evaluated before and after $30 \mathrm{~d}$ of Ramadan fasting (two meals at $12 \mathrm{~h}$ intervals). The dietary intake was estimated by $24 \mathrm{~h}$ recall before and after fasting. The total daily energy intake was decreased by 234.6 (SD 88.2) kJ/d in the fasting period $(P=0.005)$. 1/HOMA-IR, QUICKI and HDL-C were significantly increased $(P=0.005, P=0.001$ and $P=0.004)$ and FPG significantly decreased $(P<0.005)$ after fasting. Simple linear regression analysis demonstrated that HOMA-IR, 1/HOMA-IR and QUICKI were related to waist circumference after intervention $(r 0 \cdot 458, P<0 \cdot 001 ; r-0 \cdot 396$, $P<0.05 ; r-0.342, P<0.05)$. In conclusion, the present study showed that the combined change in the number and timing of meals and portioning of the entire intake into only two meals per d may increase insulin sensitivity in subjects with the metabolic syndrome even when the decrease in energy consumption is minimal.
\end{abstract}

Insulin sensitivity: Ramadan fasting: Metabolic syndrome: Homeostasis model assessment: Quantitative insulin sensitivity check index

Insulin resistance is a feature of a number of clinical disorders, including type 2 diabetes and glucose intolerance, obesity, dyslipidaemia and hypertension clustering in the so-called metabolic syndrome ${ }^{(1)}$. The prevalence of the metabolic syndrome from the Third National Health and Nutrition Examination Survey (NHANES III), as defined by the 2001 Adult Treatment Panel III criteria, was $22 \%$, with an age-dependent increase ${ }^{(2)}$ and the prevalence has continued to increase, particularly in women $^{(3)}$. Hyperinsulinaemia occurring in response to insulin resistance may play an important role in the genesis of the metabolic syndrome. Prevention or reduction of obesity, particularly abdominal obesity, is the main therapeutic goal in patients with the metabolic syndrome ${ }^{(4)}$. Weight reduction can be optimally achieved with a multimodality approach including diet, exercise, and possible pharmacological therapy, as with orlistat ${ }^{(5,6)}$. It has been shown that many different diets such as the Mediterranean diet, the dietary approach to stop hypertension (DASH) diet, diets using foods with low glycaemic index and a low-saturated fat diet may be effective in improving the metabolic syndrome by reducing insulin resistance, independent of weight loss ${ }^{(7)}$.
Ramadan is the holiest month in the Islamic calendar and during this month, Muslims fast every day from dawn to sunset. They refrain from drinking and eating for this period. The period in which the individual fasts may vary depending on the geographic location of the country and the season of the year and can be as long as $18 \mathrm{~h} / \mathrm{d}$ in the summer of the temperate regions. The physiological changes induced by Ramadan fasting are not well known. It is possible that a change in the number and timing of meals and portioning the daily food intake into two (instead of the usual four or five) could have a metabolic effect. However, conflicting results have been reported by other studies on the effects that this type of fasting may have on changes in blood glucose and insulin resistance in type 2 diabetes patients and healthy volunteers. Some studies report that this type of fasting has beneficial effects on blood glucose and lipid profile ${ }^{(8,9)}$ while other studies have shown no change in fasting blood glucose and lipid profile ${ }^{(10)}$. There are currently no reports on the effect of prolonged reduction of meal frequency on lipid profile, plasma glucose and insulin resistance indices in subjects with the metabolic syndrome. Therefore we

Abbreviations: FIRI, free immunoreactive insulin; FPG, fasting plasma glucose; HDL-C, HDL-cholesterol; HOMA-IR, homeostasis model assessment of insulin resistance; 1/HOMA-IR, reciprocal index of homeostasis model assessment of insulin resistance; QUICKI, quantitative insulin sensitivity check index.

* Corresponding author: Dr Z. Vahdat Shariatpanahi, fax +98 21 22600714, email nutritiondata@yahoo.com 
conducted a study during the month of Ramadan in order to evaluate the effects of a change in the number and timing of meals on these metabolic outcomes.

\section{Subjects and methods}

The present study was carried out in 2006 at Doctor Lavasani Hospital (Tehran, Iran). Male volunteers ( $n$ 62; age 34-61 years) with the metabolic syndrome were recruited. A participant was defined as having the metabolic syndrome if three or more of the following criteria were met, according to the National Cholesterol Education Program recommendations ${ }^{(11)}$ : (1) abdominal obesity, i.e. waist circumference $\geq 90 \mathrm{~cm}$ (the Caucasian criterion for abdominal obesity ${ }^{(12)}$ ); (2) hypertriacylglycerolaemia: $\geq 1500 \mathrm{mg} / \mathrm{l}(1.70 \mathrm{mmol} / \mathrm{l})$; (3) low HDLcholesterol (HDL-C), i.e. $<1.04 \mathrm{mmol} / 1$ (400 mg/l); (4) high blood pressure: $\geq 130 / 85 \mathrm{mmHg}$; (5) high fasting plasma glucose (FPG): $\geq 1100 \mathrm{mg} / \mathrm{l}(6 \cdot 1 \mathrm{mmol} / \mathrm{l})$. Exclusion factors were being female, type 2 diabetes mellitus, infections, stresses, acromegaly, hypertension and any addiction or drug therapy. Males were selected for the study because females are exempt from fasting during their menstrual period. Seven subjects who could not fast completely for $30 \mathrm{~d}$ were excluded from the study. All subjects were encouraged to continue their usual lifestyle and activities. The study protocol was endorsed by the appropriate ethics committee and written informed consent was obtained from each participant. After a $12 \mathrm{~h}$ overnight fast, a fasting blood sample was taken for determination of TAG, HDL-C, FPG and free immunoreactive insulin (FIRI) before intervention. Plasma glucose levels were measured by the glucose oxidase method, plasma insulin levels by immunoradiometric assay (Insulin Riabead; Dainabot, Tokyo, Japan) and HDL-C by enzymic methods adapted to an autoanalyser (Selectra; Vital Scientific, Spankeren, The Netherlands). Homeostasis model assessment of insulin resistance (HOMA-IR) and quantitative insulin sensitivity check index (QUICKI) were assessed as surrogate indices for insulin resistance and insulin sensitivity derived from fasting glucose and insulin levels ${ }^{(13,14)}$. QUICKI was calculated from FPG and FIRI levels according to the report by Katz et al. ${ }^{(15)}$, with the formula QUICKI $=1 /(\log ($ FIRI in $\mu \mathrm{U} / \mathrm{ml})+\log$ (FPG in $\mathrm{mg} / \mathrm{dl}$ )). The HOMA-IR was calculated from FPG and FIRI according to the report by Matthews et al. ${ }^{(16)}$, with the formula HOMA-IR $=$ FIRI in $\mu \mathrm{U} / \mathrm{ml} \times$ FPG in $\mathrm{mg} /$ $\mathrm{dl} / 405$. Weight was measured while the subjects were minimally clothed without shoes using digital scales and recorded to the nearest $0.1 \mathrm{~kg}$. Waist circumference was defined as the minimal abdominal circumference between the xiphoid process and the iliac crests. Dietary intake was calculated through $24 \mathrm{~h}$ recall. It was done for each participant before intervention for three non-holiday, non-consecutive, non-fasting days. This was then repeated in the fasting period. The duration of fasting was approximately $12 \mathrm{~h}$ from sunrise to sunset (the time of abstinence from food) during a $30 \mathrm{~d}$ period in the Northern hemisphere autumn season. The subjects had two meals per $\mathrm{d}$; one early in the morning about $30 \mathrm{~min}$ before sunrise, and the second immediately after sunset. Approximately $42 \%$ of their intake was in the morning meal and $58 \%$ after sunset. At the end of this period, a $12 \mathrm{~h}$ overnight fasting blood sample was taken to repeat the laboratory examinations, and weight and waist circumference were measured.

\section{Statistical methods}

SPSS software version 12 was used to analyse data (SPSS Inc., Chicago, IL, USA). Results are reported as mean values and standard deviations. Paired $t$ tests were used for comparisons of variables before and after intervention. Simple linear regression analysis was performed for analysis of association among insulin resistance indices as dependent variables with waist circumference as the independent variable. For comparisons of levels of decline in insulin resistance indices with an increase in the number of metabolic disorders Kruskal-Wallis $H$ test was used. For each variable, the significance level of 0.05 for $\alpha$ was considered.

\section{Results}

A total of fifty-five male volunteers were included in the study. The mean age of subjects was $34 \cdot 1$ (range 34-61; SD 8.9) years. Of the total, forty-nine had waist circumference $\geq 90 \mathrm{~cm}$, twenty-nine had blood pressure $\geq 130 / 85 \mathrm{mmHg}$, twenty-eight had a fasting glucose $\geq 1100 \mathrm{mg} / 1(6 \cdot 1 \mathrm{mmol} / \mathrm{l})$, thirty-nine had TAG $\geq 1500 \mathrm{mg} / \mathrm{l}(1.70 \mathrm{mmol} / \mathrm{l})$ and thirtythree had HDL $<1.04 \mathrm{mmol} / \mathrm{l}(400 \mathrm{mg} / \mathrm{l})$. Clinical characteristics and laboratory data of subjects are shown in Table 1.

The daily energy consumption during the fasting period declined by 234.6 (SD 88.2 ) kJ. This decline was statistically significant $(P=0.005)$. The percentages of decrease in weight and waist circumference measurement after the trial period were both $2.4 \%$. These reductions were statistically significant $(P<0 \cdot 001)$. QUICKI was significantly higher after fasting period $(P=0 \cdot 001)$. HOMA-IR was not affected by Ramadan fasting $(P=0.412)$ and the reciprocal index of HOMA-IR (1/HOMA-IR) increased significantly after fasting $(P=0.005)$. FPG had decreased significantly after the intervention $(P=0.005)$. Fasting plasma insulin was not significantly altered $(P=0.77)$.

Correlation coefficients of insulin resistance indices with waist circumference before and after intervention are shown in Table 2. Before and after fasting, waist circumference was related to QUICKI, 1/HOMA-IR and HOMA-IR levels in linear regression analysis. With decreasing waist circumference, QUICKI and 1/HOMA-IR levels increased linearly $(\mathrm{QUICKI}=-09.63 \times$ waist $+0.614, \quad P=0.001 ; \quad 1 / \mathrm{HOMA}-$ $\mathrm{IR}=-2.01 \times$ waist $+2.43, P=0.02)$ and with decreasing waist circumference, HOMA-IR levels decreased linearly (HOMA-IR $=0.15 \times$ waist $-11.17 ; \quad P=0.007$ ). There was no difference in levels of decline in insulin resistance indices with an increase in the number of metabolic disorders by the Kruskal-Wallis test. Systolic and diastolic blood pressures were both decreased significantly after the fasting period $(P<0.001)$ and the increase in HDL-C levels after the intervention was also significant $(P=0.004)$. Level of serum TAG increased after fasting, although its rising was not significant $(P=0 \cdot 216)$.

\section{Discussion}

The results of the present study demonstrate that Ramadan fasting can lead to some beneficial changes in FPG, HDL, insulin sensitivity and blood pressure in the metabolic syndrome. QUICKI and 1/HOMA-IR were increased significantly 
Table 1. Clinical and laboratory characteristics of the subjects before and after fasting (Mean values and standard deviations)

\begin{tabular}{|c|c|c|c|c|c|}
\hline & \multicolumn{2}{|c|}{ Before fasting } & \multicolumn{2}{|c|}{ After fasting } & \multirow[b]{2}{*}{$P$} \\
\hline & Mean & SD & Mean & SD & \\
\hline Systolic blood pressure $(\mathrm{mmHg})$ & $115 \cdot 00$ & $13 \cdot 57$ & $108 \cdot 93$ & 11.57 & $<0.001$ \\
\hline Diastolic pressure $(\mathrm{mmHg})$ & $76 \cdot 66$ & $7 \cdot 97$ & 73.78 & 6.46 & $<0.001$ \\
\hline Waist $(\mathrm{cm})$ & $94 \cdot 81$ & $7 \cdot 80$ & 91.98 & $7 \cdot 70$ & $<0.001$ \\
\hline Weight (kg) & $80 \cdot 69$ & $12 \cdot 27$ & $78 \cdot 73$ & $12 \cdot 05$ & $<0.001$ \\
\hline BMI $\left(\mathrm{kg} / \mathrm{m}^{2}\right)$ & $27 \cdot 62$ & 3.39 & $26 \cdot 87$ & 3.36 & $<0.001$ \\
\hline Total energy (kJ) & 12595 & $802 \cdot 56$ & 12361 & $661 \cdot 38$ & 0.005 \\
\hline Protein $(g)$ & $75 \cdot 14$ & 5.62 & 73.82 & 3.95 & 0.030 \\
\hline Carbohydrate (g) & $402 \cdot 99$ & $25 \cdot 62$ & $428 \cdot 18$ & 22.95 & $<0.001$ \\
\hline Fat $(g)$ & $122 \cdot 27$ & $8 \cdot 40$ & 104.99 & $5 \cdot 62$ & $<0.001$ \\
\hline HDL-cholesterol (mg/l) & $428 \cdot 7$ & 54.5 & $462 \cdot 4$ & $55 \cdot 0$ & 0.004 \\
\hline TAG $(\mathrm{mg} / \mathrm{l})$ & 2100 & $1396 \cdot 0$ & $2327 \cdot 8$ & $1088 \cdot 7$ & 0.216 \\
\hline FPG (mg/l) & 894.5 & 287.9 & $812 \cdot 1$ & $178 \cdot 4$ & 0.005 \\
\hline FIRI $(\mu \mathrm{U} / \mathrm{ml})$ & $14 \cdot 72$ & $21 \cdot 75$ & $13 \cdot 74$ & 9.47 & 0.770 \\
\hline QUICKI & 0.5161 & 0.02 & 0.5253 & 0.02 & 0.001 \\
\hline HOMA-IR & 3.73 & $6 \cdot 26$ & 2.94 & 2.58 & 0.412 \\
\hline 1/HOMA-IR & 0.5864 & 0.66 & 0.8427 & 0.38 & 0.005 \\
\hline
\end{tabular}

FPG, fasting plasma glucose; FIRI, free immunoreactive insulin; QUICKI, quantitative insulin sensitivity check index; HOMA-IR, homeostasis model assessment of insulin resistance; 1/HOMA-IR, reciprocal index of homeostasis model assessment of insulin resistance.

after fasting but there was no significant decline in HOMA-IR; this may be because HOMA-IR does not adequately predict insulin resistance in all individuals. Indeed, several investigators have reported that HOMA-IR does not correlate highly or significantly with insulin resistance, particularly in individuals with impaired glucose tolerance $e^{(17-20)}$. There was a linear increase in QUICKI and 1/HOMA-IR levels with a decreasing waist circumference. Also there was a linear decrease in HOMA-IR level with a decreasing waist circumference. Studies indicate that visceral obesity is highly correlated with insulin resistance ${ }^{(21)}$. The mean decline in energy consumption by our subjects was 234.6 (SD 88.2) $\mathrm{kJ} / \mathrm{d}$, corresponding to a mean weight reduction of 1.96 (SD 1.35) $\mathrm{kg}$ in the period of intervention. We had expected that, with this amount of decrease in daily energy consumption for 1 month, weight reduction would be about $300 \mathrm{~g}$. These changes may be due to omitting the midday meal when the body is particularly active metabolically. Fasting during the month of Ramadan is a unique metabolic model that includes abstinence from food and fluid intakes as well as from sexual activity during the period from dawn to sunset. It seems that a change in the number and timing of meals and portioning the entire intake into two (instead of the usual four or five) could have an effect on patients with the metabolic syndrome. It has been established that a given nutrient ingested at an unusual time can induce different metabolic effects ${ }^{(22)}$. During Ramadan fasting the sleep-wakefulness cycle is also altered. This leads to changes in levels of leptin, neuropeptide-Y and insulin that play an important role in the long-term regulation of energy intake and energy expenditure ${ }^{(23)}$. Also it has been shown that modifications in sleep schedules and psychological and social habits during Ramadan induce changes in the rhythmic pattern of a number of hormonal variables, i.e. melatonin, steroid hormones (cortisol, testosterone), pituitary hormones (prolactin, luteinising hormone, follicular stimulating hormone, growth hormone and thyroid-stimulating hormone) and thyroid hormones ${ }^{(24)}$. These hormones are related to energy metabolism and the regulation of energy intake. Significant changes in the proportions of dietary fats $(-15 \%)$ and carbohydrates $(+6 \%)$ as shown in Table 1 may also contribute to the observed effect on insulin resistance. Unfortunately there is no study to determine the effect of this type of fasting on the metabolic syndrome. Ziaee et al. showed that Ramadan fasting led to a decrease in fasting blood glucose and weight in healthy volunteers. Although there was a significant reduction in meal frequency, a significant increase in LDL and decrease in HDL was noted during Ramadan. Unfortunately, no data were reported about the levels of energy intake of the patients before and during Ramadan in their study ${ }^{(8)}$. Larijani et al. showed that fasting blood glucose decreases with Ramadan fasting in healthy volunteers and was positively correlated with decreased energy intake in this period $^{(9)}$. Bouguerra et al. assessed the effect of fasting during Ramadan on the metabolic profile of patients with type 2 diabetes. They concluded that Ramadan fasting causes a slight effect on glycaemia and lipoprotein levels when previous metabolic control is quite good, but fasting induces more deterioration when previous control is poor. One limitation of this study is that there are no data about energy consumption. The subjects consisted of both men and women; $30 \%$ of the patients were treated with oral

Table 2. Correlation coefficients of insulin resistance indices with waist circumference before and after fasting period

\begin{tabular}{lcc} 
& Waist before fasting period & Waist after fasting period \\
\hline QUICKI & $-0.390^{\star \star \star}$ & $-0.342^{\star \star \star}$ \\
HOMA-IR & $0.371^{\star \star \star}$ & $0.458^{\star \star}$ \\
1/HOMA-IR & $-0.600^{\star}$ & $-0.396^{\star \star \star}$ \\
\hline
\end{tabular}

QUICKI, quantitative insulin sensitivity check index; HOMA-IR, homeostasis mode assessment of insulin resistance; 1/HOMA-IR, reciprocal index of homeostasis model assessment of insulin resistance. ${ }^{\star} P<0.001,{ }^{* \star} P<0.01,{ }^{\star \star *}{ }^{*} P<0.05$. 
hypoglycaemic agents while three patients were treated through diet ${ }^{(10)}$. Yarahmadi et al. evaluated the effects of Ramadan fasting on anthropometric indices and carbohydrate and lipid metabolism in both men and women with type 2 diabetes. They found that plasma insulin, C-peptide and insulin resistance decreased significantly only in men. They concluded that Ramadan fasting does not alter carbohydrate metabolism or tissue insulin sensitivity in patients with type 2 diabetes $^{(25)}$. Again a limitation of this study is that there are no data about energy intake and also the results were focused on both female and male subjects.

A limitation of the present study is that the level of physical activity was not measured. Although we encouraged the subjects to continue their usual physical activities, one can suspect that as a result of limiting food intake, physical activities tend to decrease during the month of Ramadan fasting.

In conclusion, the present study has demonstrated that a change in the number and timing of meals and portioning of the entire daily intake into two meals may increase insulin sensitivity in the metabolic syndrome. Therefore, Ramadan fasting provides an excellent opportunity to study the effects of the prolonged reduction of meal frequency on body metabolism such as insulin sensitivity.

\section{Acknowledgements}

Our thanks go to the health deputy of the Social Security Organization, Doctor Lavasani Hospital, Alavi School and all those who contributed to the study for their valuable help and support. The source of funding for our research is the health deputy of the Social Security Organization. There are no conflicts of interest. The contribution of authors to the present study was: M. V. S. for the design of the experiment; S. S. for the provision of significant advice and consultation; Z. V. S. for the writing of the manuscript and consultation; A. H. for the collection of data; A. A. for the analysis of data.

\section{References}

1. Sesti G (2006) Pathophysiology of insulin resistance. Best Pract Res Clin Endocrinol Metab 20, 665-679.

2. Ford ES, Giles WH \& Dietz WH (2002) Prevalence of the metabolic syndrome among US adults: findings from the third National Health and Nutrition Examination Survey. JAMA 287, 356-359.

3. Ford ES, Giles WH \& Mokdad AH (2004) Increasing prevalence of the metabolic syndrome among U.S. adults. Diabetes Care 27, 2444-2449.

4. Manson JE, Skerrett PJ, Greenland P \& VanItallie TB (2004) The escalating pandemics of obesity and sedentary lifestyle. A call to action for clinicians. Arch Intern Med 164, 249-258.

5. Heymsfield SB, Segal KR, Hauptman J, Lucas CP, Boldrin MN, Rissanen A, Wilding JP \& Sjöström L (2000) Effects of weight loss with orlistat on glucose tolerance and progression to type 2 diabetes in obese adults. Arch Intern Med 160, $1321-1326$.

6. Esposito K, Marfella R, Ciotola M, Di Palo C, Giugliano F, Giugliano G, D'Armiento M, D'Andrea F \& Giugliano D (2004) Effect of a Mediterranean-style diet on endothelial dysfunction and markers of vascular inflammation in the metabolic syndrome: a randomized trial. JAMA 292, 1440-1446.
7. Minehira K \& Tappy L (2002) Dietary and lifestyle interventions in the management of the metabolic syndrome: present status and future perspective. Eur J Clin Nutr 56, 1264-1269.

8. Ziaee V, Razaei M, Ahmadinejad Z, Shaikh H, Yousefi R, Yarmohammadi L, Bozorgi F \& Behjati MJ (2006) The changes of metabolic profile and weight during Ramadan fasting. Singapore Med J 47, 409-414.

9. Larijani B, Zahedi F, Sanjari M, Amini MR, Jalili RB, Adibi $\mathrm{H} \&$ Vassigh AR (2003) The effect of Ramadan fasting on fasting serum glucose in healthy adults. Med $J$ Malaysia 58, $678-680$

10. Bouguerra R, Jabrane J, Maatki C, Ben Salem L, Hamzaoui J, El Kadhi A, Ben Rayana C \& Ben Slama C (2006) Ramadan fasting in type 2 diabetes mellitus. Ann Endocrinol 67, $54-59$.

11. Expert Panel on Detection, Evaluation, and Treatment of High Blood Cholesterol in Adults (2001) Executive Summary of the Third Report of the National Cholesterol Education Program (NCEP) Expert Panel on Detection, Evaluation, and Treatment of High Blood Cholesterol in Adults (Adult Treatment Panel III). JAMA 285, 2486-2497.

12. Inoue $\mathrm{S}$, Zimmet $\mathrm{P}$, Caterson I, Chunming C, Ikeda $\mathrm{Y}$, Khalid AK, Kim YS \& Bassett J (2000) The Asia-Pacific perspective: Redefining Obesity and its Treatment. Canberra, Australia: Health Communications Australia Pty Limited. http://www. diabetes.com.au/pdf/obesity_report.pdf

13. Chen H, Sullivan G \& Quon MJ (2005) Assessing the predictive accuracy of QUICKI as a surrogate index for insulin sensitivity using a calibration model. Diabetes 54, 1914-1925.

14. Yokoyama H, Emoto M, Fujiwara S, Motoyama K, Morioka T, Komatsu M, Tahara H, Shoji T, Okuno Y \& Nishizawa Y (2003) Quantitative insulin sensitivity check index and the reciprocal index of homeostasis model assessment in normal range weight and moderately obese type 2 diabetic patients. Diabetes Care 26, 2426-2432.

15. Katz A, Nambi SS, Mather K, Baron AD, Follmann DA, Sullivan G \& Quon MJ (2000) Quantitative insulin sensitivity check index: a simple, accurate method for assessing insulin sensitivity in humans. J Clin Endocrinol Metab 85, $2402-2410$.

16. Matthews DR, Hosker JP, Rudenski AS, Naylor BA, Treacher DF \& Turner RC (1985) Homeostasis model assessment: insulin resistance and $\beta$-cell function from fasting plasma glucose and insulin concentrations in man. Diabetologia 28, 412-419.

17. Ferrara CM \& Goldberg AP (2001) Limited value of the homeostasis model assessment to predict insulin resistance in older men with impaired glucose tolerance. Diabetes Care 24, $245-249$.

18. Anderson RL, Hamman RF, Savage PJ, Saad MF, Laws A, Kades WW, Sands RE \& Cefalu W (1995) Exploration of simple insulin sensitivity measures derived from frequently sampled intravenous glucose tolerance (FSIGT) tests. Am J Epidemiol 142, 724-732.

19. Saad MF, Anderson RL, Laws A, Watanabe RM, Kades WW, Chen Y-D, Sands RE, Pei D, Savage PJ \& Bergman RN (1994) A comparison between the minimal model and the glucose clamp in the assessment of insulin sensitivity across the spectrum of glucose tolerance. Diabetes 43, 1114-1121.

20. Yeni-Komshian H, Carantoni M, Abbasi F \& Reaven GM (2000) Relationship between several surrogate estimates of insulin resistance and quantification of insulin-mediated glucose disposal in 490 healthy nondiabetic volunteers. Diabetes Care 23, $171-175$.

21. Richelsen B \& Pedersen SB (1995) Associations between different anthropometric measurements of fatness and metabolic risk parameters in non-obese, healthy, middle-aged men. Int J Obes Relat Metab Disord 19, 169-174. 
22. Nelson W, Cadotte L \& Halberg F (1973) Circadian timing of single daily meal affects survival of mice. Proc Soc Exp Biol Med 144, 766-769.

23. Kassab S, Abdul-Ghaffar T, Nagalla DS, Sachdeva U \& Nayar U (2004) Interactions between leptin, neuropeptide-Y and insulin with chronic diurnal fasting during Ramadan. Ann Saudi Med 24, 345-349.
24. Bogdan A, Bouchareb B \& Touitou Y (2001) Ramadan fasting alters endocrine and neuroendocrine circadian patterns. Mealtime as a synchronizer in humans? Life Sci 68, 1607-1615.

25. Yarahmadi SH, Larijani B, Bastanhagh $\mathrm{MH}$, Pajouhi $\mathrm{M}$, Baradar Jalili R, Zahedi F, Zendehdel K \& Akrami SM (2003) Metabolic and clinical effects of Ramadan fasting in patients with type II diabetes. J Coll Physicians Surg Pak 13, 329-332. 